\title{
Nonsurgical management of an impacted mechanical lithotriptor with fractured traction wires: Endoscopic intracorporeal electrohydraulic shock wave lithotripsy followed by extra-endoscopic mechanical lithotripsy
}

\author{
Tan Attila MD, Gary R May MD FRCPC, Paul Kortan MD FRCPC
}

\begin{abstract}
T Attila, GR May, P Kortan. Nonsurgical management of an impacted mechanical lithotriptor with fractured traction wires: Endoscopic intracorporeal electrohydraulic shock wave lithotripsy followed by extra-endoscopic mechanical lithotripsy. Can J Gastroenterol 2008;22(8):699-702.

In a patient with a mid-common bile duct stone, the traction wires of a mechanical lithotriptor snapped, resulting in lithotriptor basket impaction. Simultaneous occurrence of these two potential complications of endoscopic stone extraction is very rarely reported. Extracorporeal shock wave lithotripsy failed to fragment the stone entrapped within the impacted basket. Endoscopic intracorporeal electrohydraulic shock wave lithotripsy successfully fragmented the stone under direct visualization through a cholangioscope. The entrapped stone within the basket could subsequently be pulled into the supra-ampullary bile duct for the final fragmentation with an extra-endoscopic mechanical lithotriptor cable. The present report is the first to describe a safe and effective use of endoscopic intracorporeal electrohydraulic shock wave lithotripsy followed by extraendoscopic mechanical lithotripsy in the management of an impacted lithotriptor basket.
\end{abstract}

Key Words: Fractured basket; Impacted bile duct stone; Lithotripsy
Prise en charge non chirurgicale d'un lithotripteur mécanique enclavé dont les fils de traction sont rompus : Lithotripsie endoscopique par ondes de choc électrohydrauliques intracorporelles, suivie de lithotripsie mécanique extra-endoscopique

Chez un patient présentant un calcul biliaire à mi-parcours du canal cholédoque, les fils de traction du lithotripteur mécanique se sont rompus, ce qui a donné lieu à un enclavement du panier du lithotripteur. L'occurrence concomitante de ces deux complications potentielles de l'extraction endoscopique des calculs est très rarement signalée. La lithotripsie par ondes de choc extracorporelles a échoué à fragmenter le calcul emprisonné dans le panier du lithotripteur. La lithotripsie endoscopique par ondes de choc électrohydrauliques intracorporelles a réussi à fragmenter le calcul sous visualisation directe, à l'aide d'un cholangioscope. Le calcul emprisonné dans le panier a pu, par la suite, être retiré vers le canal biliaire, au-dessus de l'ampoule de Vater, pour fragmentation finale avec un câble lithotripteur mécanique extraendoscopique. Le présent rapport est le premier à décrire l'utilisation sûre et efficace de la lithotripsie endoscopique par ondes de chocs électrohydrauliques extracorporelles suivie de lithotripsie mécanique extraendoscopique pour récupérer un panier de lithotripteur enclavé.
E ndoscopic retrograde cholangiopancreatography is the predominant method of treating choledocholithiasis. After endoscopic sphincterotomy, bile duct stones are successfully removed with accessories such as a Dormia basket or balloon catheters in $85 \%$ to $90 \%$ of cases (1-4). Adequate sphincterotomy, alignment of traction force to bile duct axis and removal of the distal-most stone in the presence of multiple stones are essential for successful stone extraction. Unsuccessful stone extraction is usually due to the presence of a large stone (diameter larger than $1 \mathrm{~cm}$ ) or a discrepancy between the size of the stone and the diameter of the distal bile duct. The management of nonextractable common bile duct (CBD) stones includes mechanical lithotripsy, electrohydraulic probe lithotripsy, extracorporeal shock wave lithotripsy (ESWL), laser lithotripsy and stenting until definitive stone treatment (5). Mechanical lithotripsy is the simplest and cheapest modality and is routinely performed within the same endoscopic session; a metal spiral sheath is advanced to the basket with the entrapped stone, then the handle of the cranking device is slowly turned. Lithotripsy is achieved by pulling the entrapped stone against the leading edge of the metal spiral. Sometimes, an exceptionally hard stone resists mechanical lithotripsy. In the case of failed mechanical lithotripsy, an attempt is made to dislodge the stone from the basket and the basket is retrieved. An alternative method is subsequently used for stone extraction.

We report a successful management of an impacted mechanical lithotripsy basket by endoscopic intracorporeal electrohydraulic shock wave lithotripsy followed by extraendoscopic mechanical lithotripsy.

\section{CASE PRESENTATION}

A 72-year-old Indian woman, without any significant medical history, was admitted to a local hospital with recurrent right upper quadrant and epigastric abdominal pain, and new-onset

University of Toronto, St Michael's Hospital, Advanced Therapeutic Endoscopy and Gastrointestinal Oncology Group, Toronto, Ontario

Correspondence: Dr Paul Kortan, St Michael's Hospital, Toronto, Ontario. Telephone 416-864-3094, fax 416-864-5619,

e-mail kortanp@smh.toronto.on.ca

Received for publication March 18, 2008. Accepted March 31, 2008 


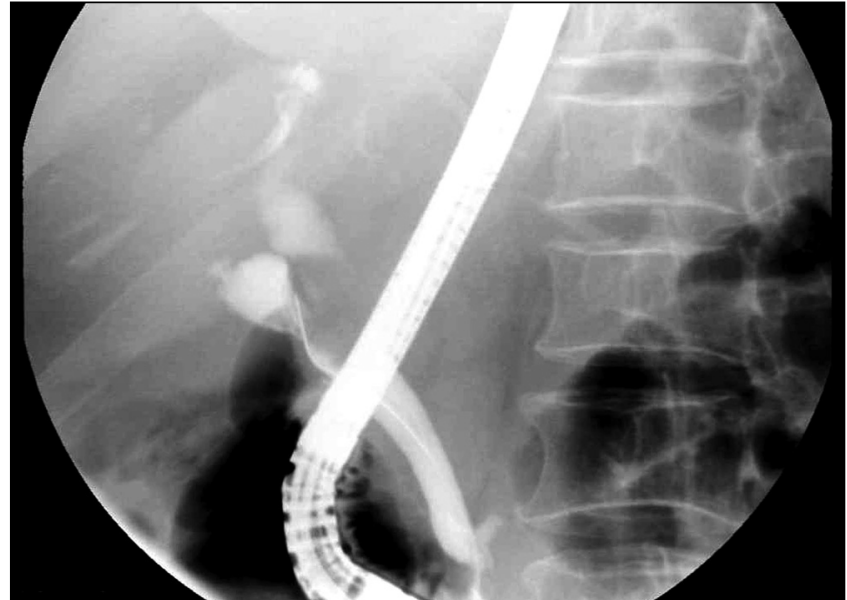

Figure 1) Cholangiography showing an immobile filling defect within the common bile duct

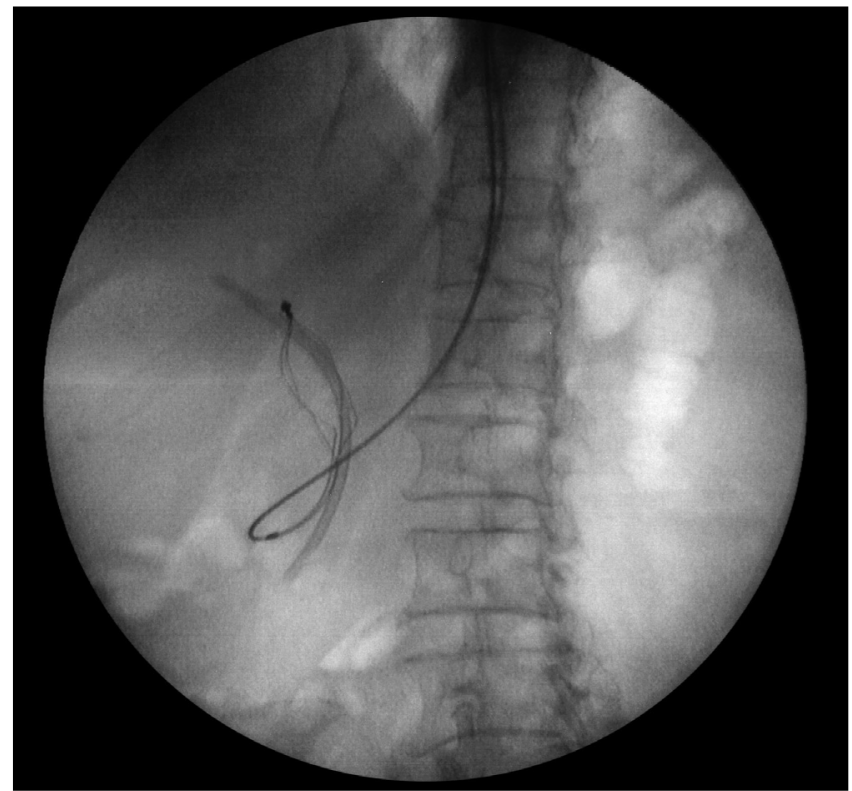

Figure 2) Fluoroscopy showing an impacted basket and a plastic stent

jaundice for a few days duration. She was febrile (temperature $39.8^{\circ} \mathrm{C}$ ) in the emergency room. Ultrasound imaging showed a dilated CBD measuring $1.4 \mathrm{~cm}$ in calibre, containing a $1.3 \mathrm{~cm}$ stone but no evidence of gallbladder stones. Blood work revealed alkaline phosphatase $355 \mathrm{U} / \mathrm{L}$ (normal $40 \mathrm{U} / \mathrm{L}$ to $130 \mathrm{U} / \mathrm{L}$ ), aspartate aminotransferase $103 \mathrm{U} / \mathrm{L}$, alanine aminotransferase $183 \mathrm{U} / \mathrm{L}$ (normal $5 \mathrm{U} / \mathrm{L}$ to $40 \mathrm{U} / \mathrm{L}$ ), total bilirubin $95 \mu \mathrm{mol} / \mathrm{L}$ (normal $1 \mu \mathrm{mol} / \mathrm{L}$ to $17 \mu \mathrm{mol} / \mathrm{L}$ ) and direct bilirubin $65 \mu \mathrm{mol} / \mathrm{L}$ (normal $1 \mu \mathrm{mol} / \mathrm{L}$ to $4 \mu \mathrm{mol} / \mathrm{L}$ ). White blood cell count was elevated at $13.7 \times 10^{9} / \mathrm{L}$. Antibiotics were started. An endoscopic retrograde cholangiography (ERC) at a local hospital revealed a large immobile filling defect in the mid-CBD. The patient was referred to the endoscopy unit for further management.

The ERC revealed a solitary mid-CBD filling defect consistent with a stone $(1.3 \mathrm{~cm}$ in diameter) (Figure 1$)$. The endoscopic sphincterotomy was extended. The stone was entrapped with a mechanical lithotriptor basket (BML Lithotriptor; Olympus America Corp, USA). The metal spiral sheath

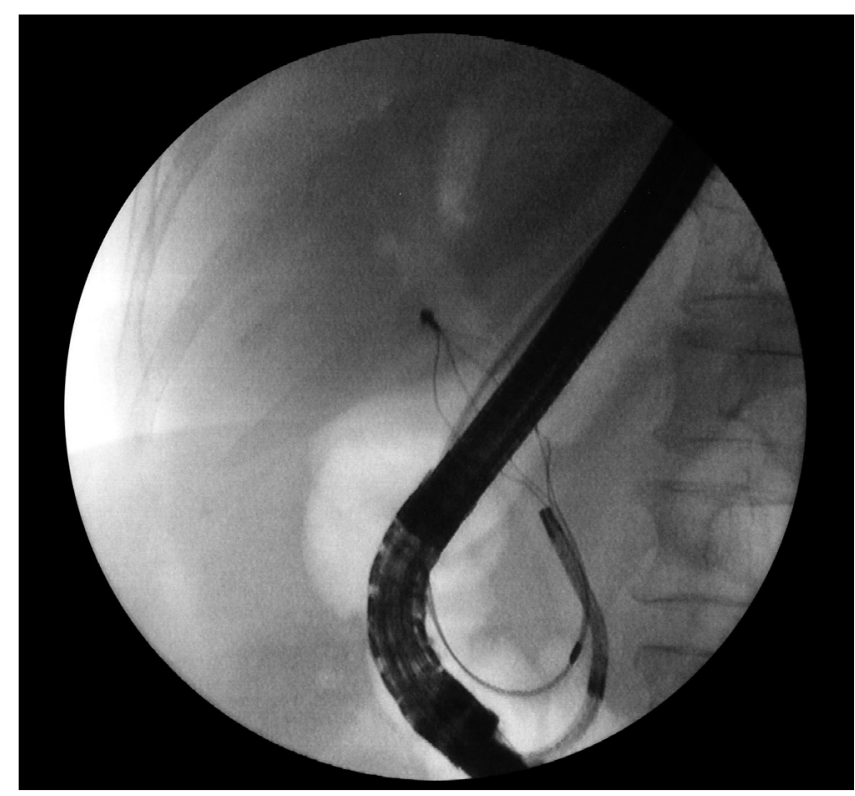

Figure 3) Fluoroscopy showing an impacted basket and direct choledochoscope through the mother scope

advanced to the basket with the entrapped stone; subsequently, the handle of the cranking device was slowly turned. The stone was extremely hard and the wire of the mechanical lithotriptor snapped at the handle portion of the basket; hence, the basket with the entrapped stone was impacted within the mid-CBD. Rat-tooth forceps, alligator forceps and a second basket were unsuccessfully used in attempts to disengage the stone from the broken basket. A $9 \mathrm{~cm}$ long 10 Fr plastic stent was placed to facilitate drainage (Figure 2). The basket wires initially exiting the mouth were then converted to the nasal route and a nasogastric tube was placed over the wires to prevent local irritation of nasogastrointestinal mucosa.

To fragment the stone, ESWL was attempted. Three thousand shock waves were applied at an energy level of $24 \mathrm{kV}$. The following day, ERC revealed persistence of the impacted stone without any fragmentation. Once again, neither attempts to disengage the impacted basket nor mechanical lithotripsy with a second basket were successful.

On the following day, an ERC was repeated using a mother-daughter system (TJF M20, Olympus Optical, Japan) with direct cholangioscopy (CHF-BP 30, Olympus Optical, Japan). The entrapped stone and basket wires were visualized (Figures 3 and 4). Successful stone fragmentation was achieved using intracorporeal electrohydraulic shock wave lithotripsy (Northgate Research Inc, USA) at an energy level of $75 \mathrm{~W}$ (Figure 5). Multiple small stone fragments were extracted. Although the lithotripsy basket could not be completely removed, it was pulled to the supra-ampullary bile duct, where a safe final fragmentation of the stone within the impacted basket was completed with an extra-endoscopic mechanical lithotriptor (Soehendra lithotriptor cable, Cook Medical, USA) (Figure 6). Finally, the broken basket was removed. All of the stone fragments were successfully removed with multiple basket and balloon sweeps. At the end of the procedure, excellent bile drainage was noted. The patient's condition clinically and biochemically improved, and she was discharged home. 


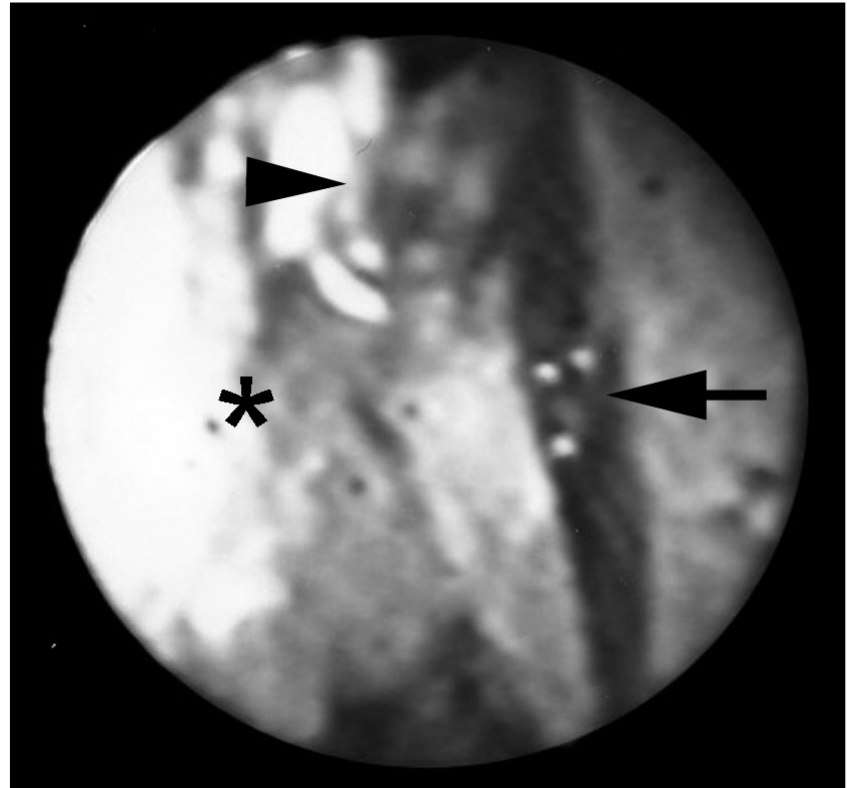

Figure 4) Cholangioscopy showing a stone (asterisk), an impacted basket wire (arrow) and the tip of an intracorporeal electrohydraulic shock wave lithotriptor (arrowhead)

\section{DISCUSSION}

The treatment of bile duct stones has evolved from surgery to endoscopic management, with a success rate of $90 \%$ (6). However, endoscopic stone removal becomes challenging and sometimes impossible in the presence of a large stone. Mechanical lithotripsy has been successfully used in $80 \%$ to $90 \%$ of cases to crush CBD stones that are too large to remove by conventional methods (7-9). Commercially available mechanical lithotriptors are divided into two types. Throughthe-scope lithotripsy baskets are inserted through the accessory channel of a duodenoscope, and the metal sheath is advanced up to the engaged stone within the basket and the stone is fragmented by using a crank handle (eg, BML lithotripter). The other type is used after removal of the duodenoscope; a spiral metal sheath is advanced over the basket wires under fluoroscopic guidance and the engaged stone is crushed by the crank handle (eg, Soehendra lithotriptor cable). The latter lithotriptor can only be used for supra-ampullary stones because there is increased risk for perforation with proximally located stones (personal communication with Dr Nib Soehendra and our institutional experience).

Stone impaction, stone size and stone size to bile duct diameter ratio (greater than 1) are predictors of unsuccessful mechanical lithotripsy (10-12). Impaction of the lithotripsy basket during endoscopic removal of a CBD stone is seen in up to $5.9 \%$ of cases $(13,14)$. Nasobiliary or internal biliary drainage is temporarily used to decrease the risk of cholangitis. However, removal of the impacted basket is essential. Rupture of the traction wire at the handle may be prevented by using baskets with a predetermined breaking point at the base or tip of the lithotriptor basket (15). This feature may prevent some cases of basket impaction. Although impacted baskets are commonly managed surgically (16), an extensive literature search revealed several nonsurgical therapeutic options.

Although spontaneous passage of an impacted basket has been reported (17-19), traction wires may potentially cause

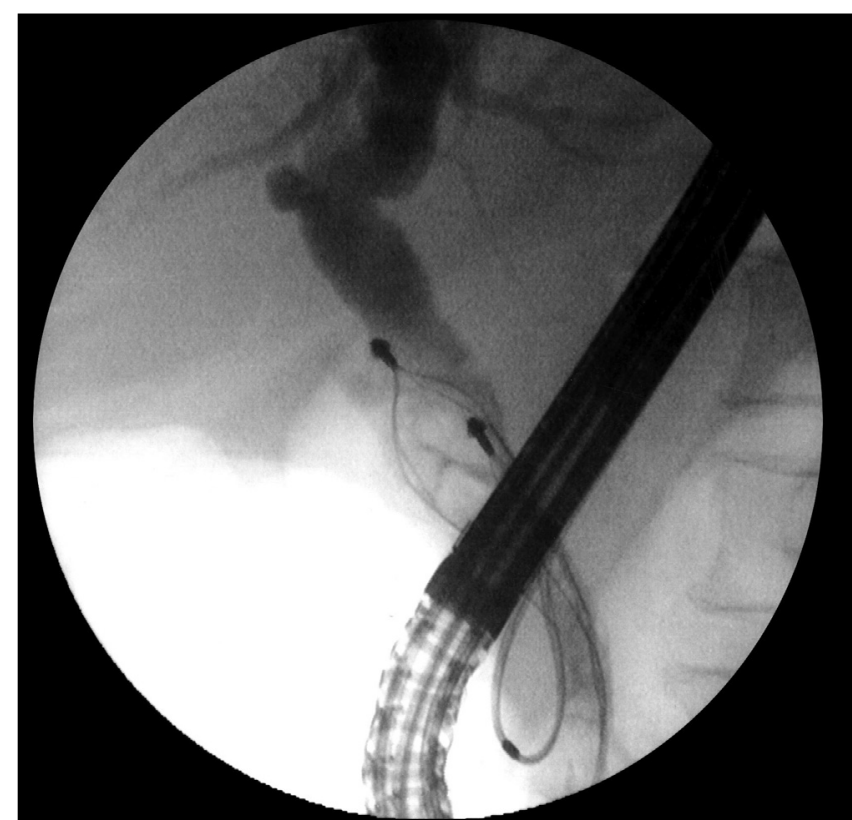

Figure 5) Fluoroscopy revealing fragmented stone particles following intracorporeal electrohydraulic shock wave lithotripsy with a second basket to remove stone fragments

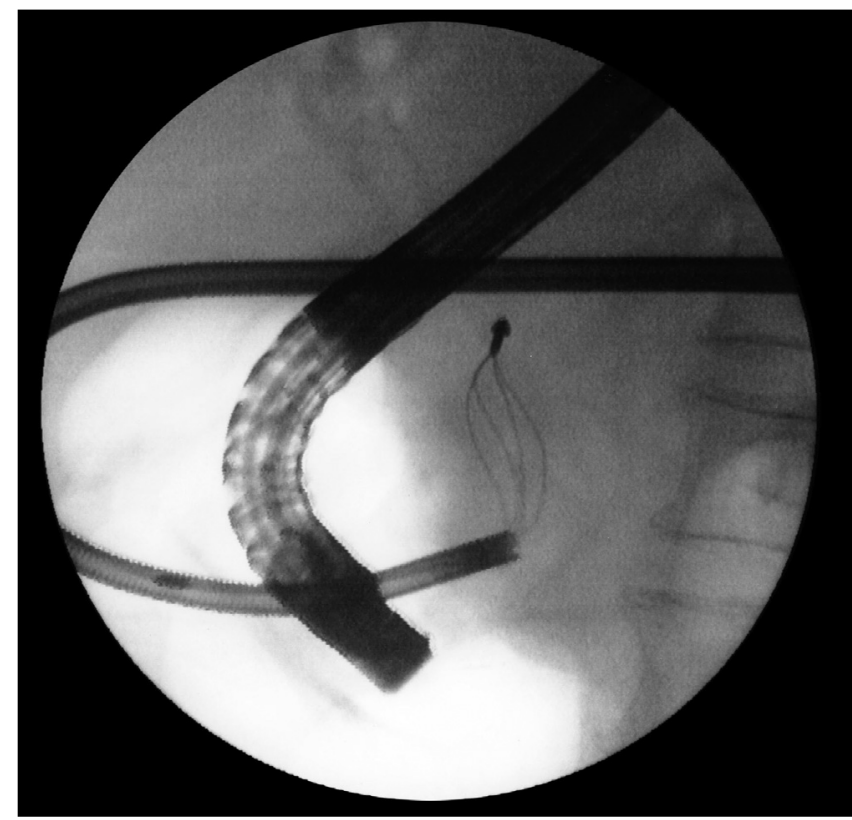

Figure 6) Fluoroscopy showing final fragmentation of the stone within the impacted basket, which was completed with a Soehendra metal sheath (Cook Medical, USA) introduction over the wires

mucosal injury. Impacted baskets located at the distal bile duct have been traditionally managed with the use of an extraendoscopic mechanical lithotriptor (Soehendra lithotriptor). With this technique, the duodenoscope is initially removed before mechanical lithotripsy. Following lithotripsy, the duodenoscope is reintroduced to clear the bile duct from fragmented stone particles. Recently, several newly developed through-the-scope lithotriptors have been introduced for the management of basket impaction in the CBD (20-22). Alternatively, a second through-the-scope mechanical 
lithotriptor can be used to crush the stone within the impacted mechanical lithoptripsy basket (23). In a case of traction wire fracture of a mechanical lithotriptor, successful continuation of the mechanical lithotripsy procedure was achieved by replacing the long metal sheath stepwise with shorter ones $(70 \mathrm{~cm}$, $60 \mathrm{~cm}$ and $50 \mathrm{~cm}$, respectively) (24). An impacted Dormia basket can be disengaged from the stone with the help of a second basket by initially pulling the tip of the original basket proximally into the wider biliary lumen and subsequently flipping it downward (25). ESWL has been used to disintegrate the captured stone within an impacted basket (26). Sauter et al (14) successfully removed an impacted Dormia basket in 11 of 12 patients after a single session of ESWL. The impacted stone in the remaining patient was disintegrated after three treatment sessions. When complete fragmentation of a stone within an impacted basket cannot be achieved by ESWL, laser lithotripsy by itself (27) or laser lithotripsy followed by

\section{REFERENCES}

1. Cotton PB. Endoscopic management of bile duct stones; (apples and oranges). Gut 1984;25:587-97.

2. Sivak MV Jr. Endoscopic management of bile duct stones. Am J Surg 1989;158:228-40.

3. Binmoeller KF, Schafer TW. Endoscopic management of bile duct stones. J Clin Gastroenterol 2001;32:106-18.

4. Cotton PB. Non-operative removal of bile duct stones by duodenoscopic sphincterotomy. Br J Surg 1980;67:1-5.

5. Hochberger J, Tex S, Maiss J, Hahn EG. Management of difficult common bile duct stones. Gastrointest Endosc Clin N Am 2003;13:623-34.

6. Neuhaus H. Endoscopic and percutaneous treatment of difficult bile duct stones. Endoscopy 2003;35:S31-4.

7. Van Dam J, Sivak MV Jr. Mechanical lithotripsy of large common bile duct stones. Cleve Clin J Med 1993;60:38-42.

8. Chung SC, Leung JW, Leong HT, Li AK. Mechanical lithotripsy of large common bile duct stones using a basket. Br J Surg 1991;78:1448-50.

9. Hintze RE, Adler A, Veltzke W. Outcome of mechanical lithotripsy of bile duct stones in an unselected series of 704 patients. Hepatogastroenterology 1996;43:473-6.

10. Cipolletta L, Costamagna G, Bianco MA, et al. Endoscopic mechanical lithotripsy of difficult common bile duct stones. Br J Surg 1997;84:1407-9.

11. Garg PK, Tandon RK, Ahuja V, Makharia GK, Batra Y. Predictors of unsuccessful mechanical lithotripsy and endoscopic clearance of large bile duct stones. Gastrointest Endosc 2004;59:601-5.

12. Lee SH, Park JK, Yoon WJ, et al. How to predict the outcome of endoscopic mechanical lithotripsy in patients with difficult bile duct stones? Scand J Gastroenterol 2007;42:1006-10.

13. Schneider MU, Matek W, Bauer R, Domschke W. Mechanical lithotripsy of bile duct stones in 209 patients - effect of technical advances. Endoscopy 1988;20:248-53.

14. Sauter G, Sackmann M, Holl J, Pauletzki J, Sauerbruch T, Paumgartner G. Dormia baskets impacted in the bile duct: Release by extracorporeal shock-wave lithotripsy. Endoscopy 1995;27:384-7.

15. Hochberger J, Tex S, Maiss J, Hahn EG. Management of difficult common bile duct stones. Gastrointest Endosc Clin N Am 2003; 13:623-34.

16. Cid JA, Lobo DN. Impacted biliary basket. Gastrointest Endosc 2005;61:110-1.

17. Leese T, Neoptolemos JP, Carr-Locke DL. Successes, failures, early complications and their management following endoscopic mechanical lithotripsy (28) can be used to remove a retained basket. Intracorporeal electrohydraulic shock wave lithotripsy has been successfully used for biliary stone disease $(29,30)$. It was also used in impacted-basket management through a percutaneous transhepatic approach (31).

The present case report indicates that endoscopic intracorporeal electrohydraulic shock wave lithotripsy can be safely and effectively applied with direct visualization even after failure of ESWL to fragment a stone entrapped within an impacted mechanical lithotriptor basket. Because this technique can only be safely applied with direct visualization through direct cholangioscopy, it requires special equipment and technical expertise. The fragmented stone within the basket at the supra-ampullary bile duct was safely and successfully crushed with an extra-endoscopic mechanical lithotriptor cable. If the options mentioned above fail or are unavailable, an open or laparoscopic surgical exploration is required.

sphincterotomy: Results in 394 consecutive patients from a single centre. Br J Surg 1985;72:215-9.

18. Nuehaus B, Safrany L. Complications of endoscopic sphinecterotomy and their treatment. Endoscopy 1981;13:197-9.

19. Maple JT, Baron TH. Biliary-basket impaction complicated by in vivo traction-wire fracture: Report of a novel management approach. Gastrointest Endosc 2006;64:1031-3.

20. Draganov P, Cunningham JT. Novel "through-the-endoscope" technique for removing biliary stones trapped in a retrieval basket. Endoscopy 2002;34:176.

21. Matsushita M, Takakuwa H, Matsubayashi Y, et al. Through-theendoscope technique for retrieval of impacted biliary baskets with trapped stones. Am J Gastroenterol 2004;99:1198-9.

22. Nakatsu T, Uchida N, Ogawa M, et al. Newly developed endotriptor for patients with basket impaction in the distal common bile duct. Endoscopy 2006;38:433.

23. Ng EK, Lau JY, Chung SC, Li AK. Retrieval of an impacted mechanical lithotripsy basket. Endoscopy 1997;29:128.

24. Hintze RE, Adler A, Veltzke W, Ramani NV, Abou-Rebyeh H. Management of traction wire fracture complicating mechanical basket lithotripsy. Endoscopy 1997;29:883-5.

25. Ranjeev P, Goh K. Retrieval of an impacted Dormia basket and stone in situ using a novel method. Gastrointest Endosc 2000;51:504-6.

26. Merrett M, Desmond P. Removal of impacted endoscopic basket and stone from the common bile duct by extracorporeal shock waves. Endoscopy 1990;22:92.

27. Neuhaus H, Hoffmann W, Classen M. Endoscopic laser lithotripsy with an automatic stone recognition system for basket impaction in the common bile duct. Endoscopy 1992;24:596-9.

28. Schutz SM, Chinea C, Friedrichs P. Successful endoscopic removal of a severed, impacted Dormia basket. Am J Gastroenterol 1997;92:679-81.

29. Adamek HE, Schneider AR, Adamek MU, et al. Treatment of difficult intrahepatic stones by using extracorporeal and intracorporeal lithotripsy techniques: 10 years' experience in 55 patients. Scand J Gastroenterol 1999;34:1157-61.

30. Seitz U, Bapaye A, Bohnacker S, Navarrete C, Maydeo A, Soehendra N. Advances in therapeutic endoscopic treatment of common bile duct stones. World J Surg 1998;22:1133-44.

31. Sheridan J, Williams TM, Yeung E, Ho CS, Thurston W. Percutaneous transhepatic management of an impacted endoscopic basket. Gastrointest Endosc 1993;39:444-6. 


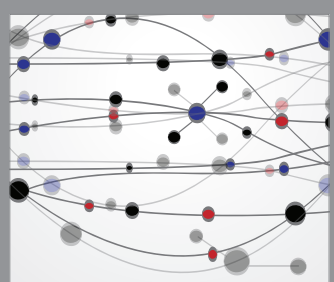

The Scientific World Journal
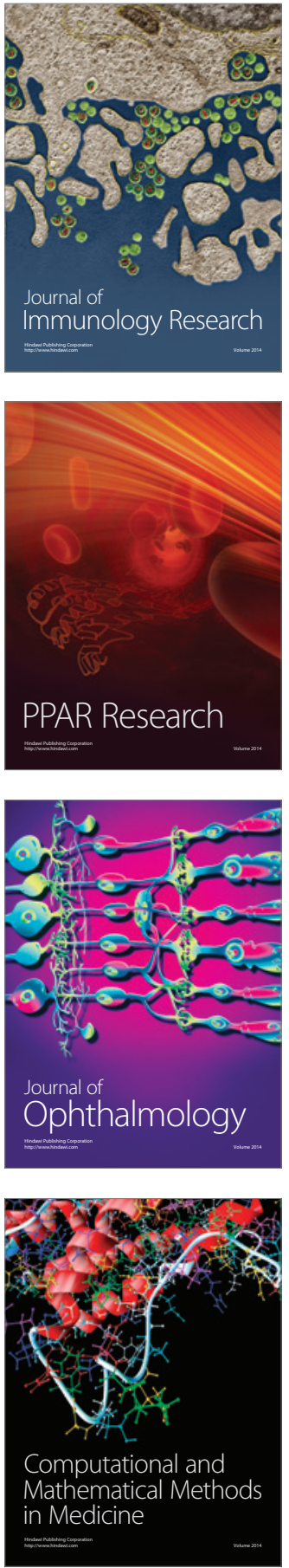

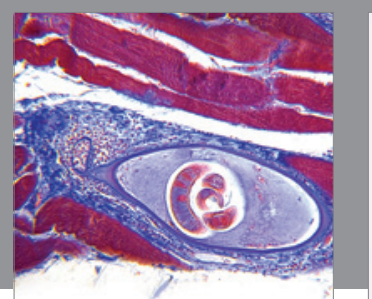

Gastroenterology Research and Practice

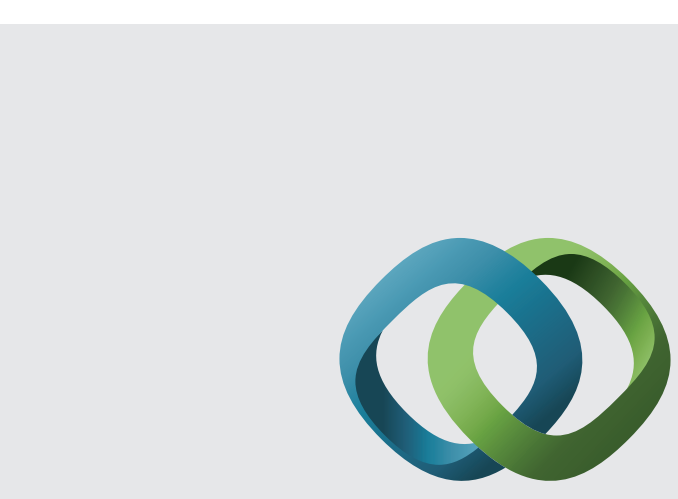

\section{Hindawi}

Submit your manuscripts at

http://www.hindawi.com
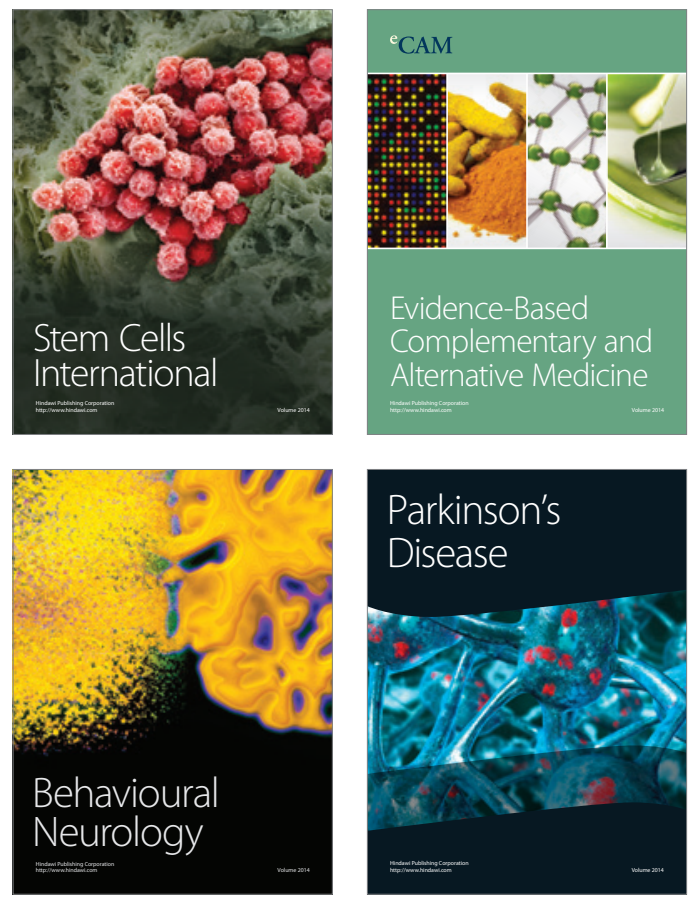
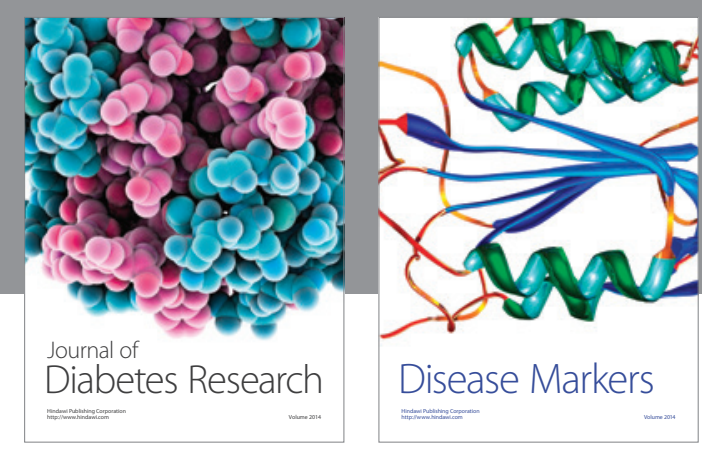

Disease Markers
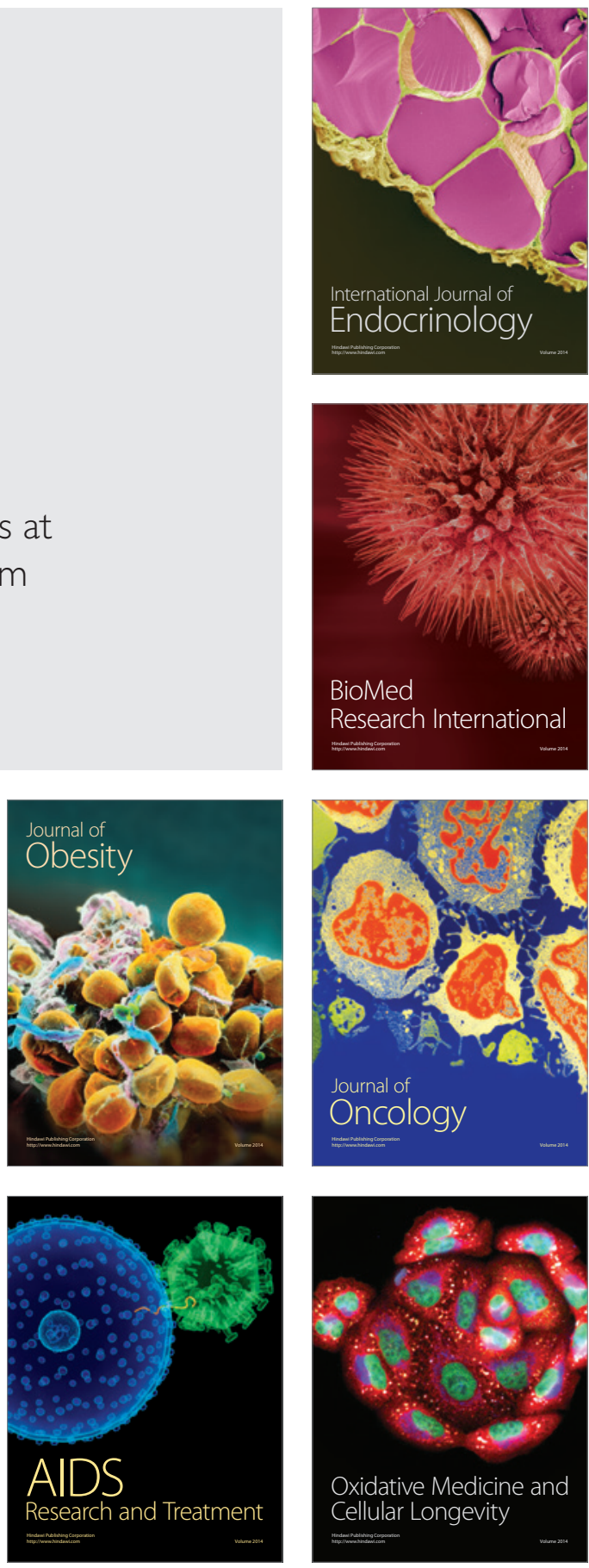